\title{
One-Bead-One-Peptide Library to Purify Crotalus durissus terrificus Phosholipase A2
}

\author{
María C. Martínez-Ceron ${ }^{1 * \dagger}$, Soledad L. Saavedra ${ }^{1}$, Lucía Ávila ${ }^{2 \dagger}$, \\ Silvana L. Giudicessi ${ }^{1}$, Fernando Albericio ${ }^{3,4}$, Silvia A. Camperi ${ }^{1}$ \\ and Osvaldo Cascone ${ }^{1,2}$
}

${ }^{I}$ NANOBIOTEC Institute, UBA-CONICET, Cathedra of Biotechnology, School of Pharmacy and Biochemistry, UBA, CABA, 1113, Argentina; ${ }^{2}$ National Institute of Biologicals Production, ANLIS-Malbrán, CABA, 1281, Argentina; ${ }^{3}$ IRB-PCB, UB. Barcelona, 08028, Spain; ${ }^{4}$ School of Chemistry, Yachay Tech, Yachay City of Knowledge, Urcuqui, 100650, Ecuador

*camartinez@ffyb.uba.ar, both contributed equally to this work

\section{Introduction}

Crotalus durissus terrificus (Cdt) is the only species of that genus in Argentina. Crotoxin represents more than $50 \%$ of the dry weight of its venom. This protein has two subunits: A (phospholipase A2, PLA2), and B (crotapotin). The venom protein profile differs according to geographical regions and contain several biologically active molecules [1,2]. Muller, et al [3] evaluated the antiviral activity of isolated toxins from Cdt and found that PLA2 strongly inhibits the yellow fever and dengue viruses growth in VERO E6 cells.

The aim of this work was to design a high performance purification method of Argentinean Cdt PLA2 by affinity chromatography with ligands selected from the screening of peptidic combinatorial libraries. Affinity chromatography is the better choice to purify proteins from complex mixtures like

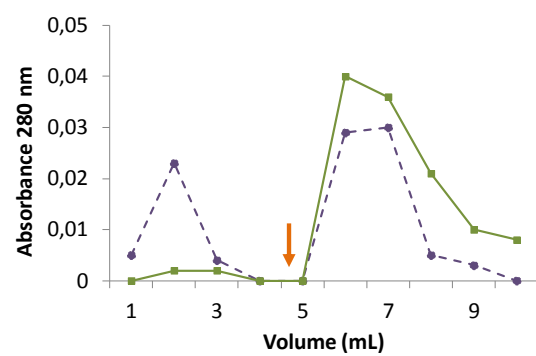

Fig. 1. Pure PLA2 chromatography on P1Sepharose (--•--) (adsorption buffer: $20 \mathrm{mM}$ sodium phosphate, $\mathrm{pH} 7.0)$ and on P2-Sepharose (-n-) (adsorption buffer: $20 \mathrm{mM}$ sodium phosphate, $p H$ 8.0). The arrow indicates the buffer change. snake venoms. Short peptides, as affinity ligands, are stable and resistant to proteases and can be produced in high quantities and purity. The challenge is to find a peptide ligand with enough affinity to use in industrial-scale chromatography [4]. Divide-couple-recombine (DCR) method allows obtaining a library with all possible combinations of the amino acids in the form of "one bead-one peptide". Peptide ligands can be selected from library screening $[5,6]$. We have developed a rapid and non-expensive strategy for the identification of peptides contained on positive beads by using matrix-assisted laser desorption/ionization time-of-flight mass spectrometry (MALDI-TOF-MS), and 4-hydroxymethylbenzoic acid (HMBA) as the linker in order to introduce a cleavage site to release the peptides from matrix before MS analysis [7,8].

\section{Results and Discussion}

A combinatorial library containing the decapeptides XXXXXGGAGG where X= A, E, F, H, L, N, P, $\mathrm{R}, \mathrm{S}, \mathrm{T}, \mathrm{V}$ or $\mathrm{Y}$ was synthesized on HMBA-ChemMatrix resin by the DCR method using Fmoc chemistry as previouly described [4]. The screening was carried out using pure PLA2 labeled with NHS-Biotin. Those peptidyl-beads with affinity for the protein were revealed using StreptavidinPeroxidase and $\alpha$-Chloronaphtol/ $\mathrm{H}_{2} \mathrm{O}_{2}$. Those beads that turned to violet colour were isolated to release the peptides from HMBA-ChemMatrix resin using ammonia vapor. Then, the peptides were analyzed by MALDI-TOF MSMS to determinate their sequence. We sequenced 50 peptides and studied their amino acid frequences and moieties. Peptide 1 and Peptide 2 were selected to be immobilized in Sepharose. 


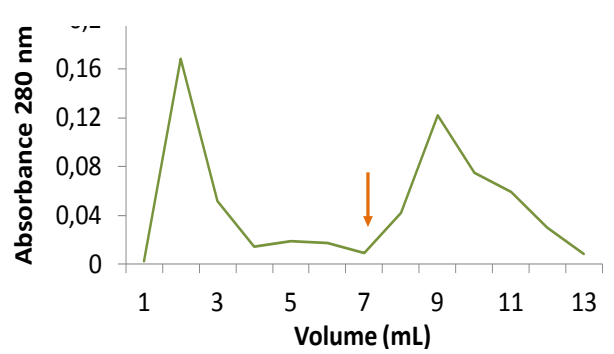

Fig. 2. Cdt whole venom chromatography on P2-Sepharose (adsorption buffer: 20 $m M$ sodium phosphate, $p H$ 8.0, buffer) and PLA2 purification. The arrow indicates buffer change.
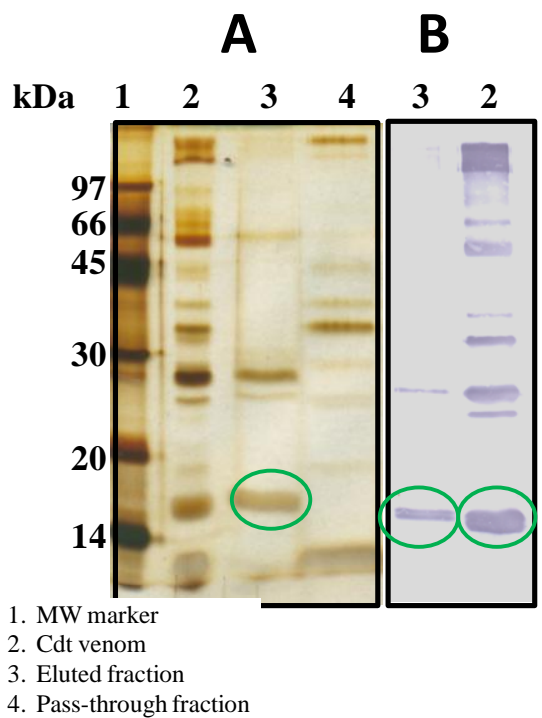

Fig. 3. (A) SDS-PAGE of Cdt's venom fractionation Silver staining and (B) Western Blot analysis of whole venom and elution fraction. The circle indicates the PLA2 band.

\section{References}

1. Faure, G., et al. Eur. J. Biochem. 223, 161-164 (1994), http://dx.doi.org/10.1111/j.1432-1033.1994.tb18978.x

2. Hernandez-Oliveira, S., et al. Protein J. 24, 233-242 (2005), http://dx.doi.org/10.1007/s10930-005-6718-z

3. Müller, V.D.M., et al. Toxicon 59, 507-515 (2012), http://dx.doi.org/10.1016/j.toxicon.2011.05.021

4. Camperi, S.A., et al. Labrou, N. (Ed.) Methods in Molecular Biology: Protein Downstream Processing,

Humana Press Inc. Springer, New York, 2014, Vol. 1129, p. 277-302, http://dx.doi.org/10.1007/978-1-62703-977-2_22

5. Furka, A., et al. Int. J. Peptide Protein Res. 37, 487-493 (1991), http://dx.doi.org/10.1111/j.13993011.1991.tb00765.x

6. Lam, K.S., et al. Nature 354, 82-84 (1991), http://dx.doi.org/10.1038/354082a0

7. Marani, M.M., et al. J. Comb. Chem. 11, 146-150 (2009), http://dx.doi.org/10.1021/cc800145c

8. Martínez-Ceron, M.C., et al. Anal. Biochem. 400, 295-297 (2010), http://dx.doi.org/10.1016/j.ab.2010.01.029
Pure samples of PLA2 in equilibrating buffer were columns were washed with equilibrating buffer until the (1ts initial value. The 8.0. The elution was performed with $100 \mathrm{mM}$ sodium achieved by employing $20 \mathrm{mM}$ sodium phosphate, $\mathrm{pH}$ , as the adsorption buffer and for P2-Sepharose by

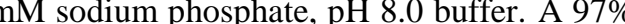
matrix, while the adsorption percentage with Sepharose was only 70\% (Figure 1). Therefore, P2A matrix was used for further experiments. column filled with P2 matrix, and PLA2 was adsorbed and eluted quantitatively. When Cdt 列 only appears in the elution fraction (Figure $3 \mathrm{~A}$ ). The horse IgG-peroxidase (Figure $3 \mathrm{~B}$ ).

chromatography with peptide ligands are an efficient diseases.

This work was partially supported by the National Scientific Technological Research Council (Consejo Nacional de Argentina) (CONICET), ANPCyT PICT. PICT-2012-1881, (11220130100119CO, the University of Buenos Aires S.L.G, S.A.C and O.C are researchers of the CONICET. We thank Simon Côté from Matrix Innovation Inc. for generous donation of HMBA-ChemMatrix resin. te buffer, $\mathrm{pH} 3.0,0.25 \mathrm{M} \mathrm{NaCl}$. performed with crotalic horse antivenom and rabbit 